\title{
Signaling by Sensory Receptors
}

\author{
David Julius ${ }^{1}$ and Jeremy Nathans ${ }^{2}$ \\ ${ }^{1}$ Department of Physiology, University of California School of Medicine, San Francisco, California 94158 \\ ${ }^{2}$ Department of Molecular Biology and Genetics, Johns Hopkins Medical School, Baltimore, Maryland 21205 \\ Correspondence: David.Julius@ucsf.edu and jnathans@jhmi.edu
}

\section{SUMMARY}

Sensory systems detect small molecules, mechanical perturbations, or radiation via the activation of receptor proteins and downstream signaling cascades in specialized sensory cells. In vertebrates, the two principal categories of sensory receptors are ion channels, which mediate mechanosensation, thermosensation, and acid and salt taste; and G-protein-coupled receptors (GPCRs), which mediate vision, olfaction, and sweet, bitter, and umami tastes. GPCRbased signaling in rods and cones illustrates the fundamental principles of rapid activation and inactivation, signal amplification, and gain control. Channel-based sensory systems illustrate the integration of diverse modulatory signals at the receptor, as seen in the thermosensory/pain system, and the rapid response kinetics that are possible with direct mechanical gating of a channel. Comparisons of sensory receptor gene sequences reveal numerous examples in which gene duplication and sequence divergence have created novel sensory specificities. This is the evolutionary basis for the observed diversity in temperature- and liganddependent gating among thermosensory channels, spectral tuning among visual pigments, and odorant binding among olfactory receptors. The coding of complex external stimuli by a limited number of sensory receptor types has led to the evolution of modality-specific and species-specific patterns of retention or loss of sensory information, a filtering operation that selectively emphasizes features in the stimulus that enhance survival in a particular ecological niche. The many specialized anatomic structures, such as the eye and ear, that house primary sensory neurons further enhance the detection of relevant stimuli.

\section{Outline}

1 Introduction

2 Receptors: Detection and Transduction

3 Structural Basis of Sensory Receptor Activation

4 The Logic of Sensory Coding
5 Evolution and Variation

6 Concluding Remarks

References

Editors: Lewis Cantley, Tony Hunter, Richard Sever, and Jeremy W. Thorner

Additional Perspectives on Signal Transduction available at www.cshperspectives.org

Copyright $\odot 2012$ Cold Spring Harbor Laboratory Press; all rights reserved; doi: 10.1101/cshperspect.a005991 


\section{INTRODUCTION}

An organism's perception of the world is filtered through its sensory systems. The properties of these systems dictate the types of stimuli that can be detected and constrain the ways in which these stimuli are reconstructed, integrated, and interpreted. Here we discuss how sensory signals are received and transduced, focusing on the first steps in the complex process of perceiving an external stimulus. A recurrent theme is the way in which the biochemical and biophysical properties of sensory receptor molecules, and the neurons in which they reside, have been sculpted by evolution to capture those signals that are most salient for the survival and reproduction of the organism. As a result, some classes of sensory receptors, such as the night vision receptor rhodopsin, show great conservation, whereas others, such as olfactory receptors, show great diversity.

Evolutionary comparisons are fascinating at many levels, not least of which is their power to highlight the logic of the stimulus-response relationship. For example, honeybees can see UV light, enabling them to locate sources of nectar and pollen based on the UV reflectance of flower petals (Kevan et al. 2001), whereas humans and Old World primates have excellent sensitivity and chromatic discrimination at longer wavelengths, permitting the identification of red, orange, and yellow fruit against a background of green foliage (Mollon 1989). Star-nosed moles use a specialized mechanoreceptive organ on their snout to locate meals and navigate through lightless subterranean tunnels (Catania 2005), and pit vipers have evolved thermoreceptive organs to detect the infrared radiation emitted by their warm-blooded prey (Campbell et al. 2002). In each of these cases, evolution has fine-tuned a sensory organ through anatomical and/or molecular changes to enhance the detection of relevant stimuli.

For simplicity, we focus on eukaryotic sensory systems, in which G-protein-coupled receptors (GPCRs) and ion channels predominate as sensory receptors. The one exception is mechanosensation, in which the molecular basis of membrane stretch detection has been beautifully delineated in bacteria but remains less clear in eukaryotes. Thus, our discussion of mechanosensation is focused largely on prokaryotic systems. We also describe the diverse cast of downstream transduction pathways and the manner in which receptors and transduction pathways are regulated to terminate signaling and set receptor sensitivity.

Before discussing individual receptors, it is worth noting that the physiological attributes of sensory systems are dictated not only by the molecular properties of receptor molecules and their associated signal transduction proteins, but also by the architecture of the sensory organs, cells, and subcellular structures in which they reside. A notable example is the retina, where visual pigments, together with other components of the phototransduction pathway, are localized within outer segments of rod and cone photoreceptor cells at near millimolar concentrations, thereby enhancing light sensitivity and transduction efficiency (Yau and Hardie 2009). Another example is seen in the cochlea, where sound pressure waves are transmitted through the middle ear to induce a localized and frequency-dependent distortion of the basilar membrane in the cochlea. Progressive changes in both the mechanical properties of the basilar membrane and the electrical properties of the auditory hair cells along the length of the cochlea generate a tonotopic map in which the amplitudes of different frequency components in a complex sound are reflected in the magnitudes of auditory receptor activation at different locations within the cochlea (Roberts et al. 1988).

\section{RECEPTORS: DETECTION AND TRANSDUCTION}

Both GPCRs and ion channels contribute to sensory transduction pathways by initiating or modulating stimulusevoked responses (Fig. 1; Table 1). In vertebrates, GPCRs predominate as stimulus detectors in vertebrate visual and olfactory receptor cells. In contrast, recent studies suggest that fly olfactory neurons use ionotropic glutamate receptor-like channels to detect some classes of odorants (Benton et al. 2009), revealing a striking divergence of signal transduction mechanisms between insect and vertebrate chemosensory systems. Ion channels predominate in the detection of auditory and somatosensory stimuli, and both GPCRs and ion channels serve as stimulus detectors in the gustatory (taste) system.

Because GPCRs transduce information through multicomponent second-messenger-based "metabotropic" signaling pathways (Henrik-Heldin et al. 2012), they endow physiological systems with a tremendous capacity for signal amplification (Fig. 2). In vertebrate chemosensory and visual systems, GPCR-based signaling enables sensory cells to detect nanomolar concentrations of ligands or single photons, respectively. Such high sensitivity is possible because a single GPCR, during its active lifetime, can activate dozens to hundreds of $G$ proteins, and each activated $G$ protein in conjunction with its associated target enzyme can synthesize or destroy thousands of second-messenger molecules. This type of signaling cascade has been most thoroughly analyzed in vertebrate rod photoreceptors, where light-evoked activation of a single rhodopsin molecule leads to the activation of about 500 downstream effector proteins [the $\mathrm{G}$ protein transducin and its associated cyclic (c)GMP phosphodiesterase], with the consequent hydrolysis of about 100,000 molecules of cGMP per second (Fig. 1A) (Stryer 1986; Arshavsky et al. 2002). 
The reduction in cytosolic cGMP leads to the closure of cGMP-gated ion channels in the outer segment plasma membrane, thereby hyperpolarizing the cell and decreasing the release of the neurotransmitter glutamate onto bipolar cells, the second-order neurons within the retina.

A similar biochemical logic governs signaling in vertebrate olfactory sensory neurons, where activation of G-protein-coupled odorant receptors increases the synthesis of cAMP, which binds directly to and thereby opens cyclicnucleotide-gated ion channels in the plasma membrane of olfactory cilia (Fig. 1B). The resulting depolarization of the plasma membrane initiates an action potential that is transmitted from the sensory neuron's body in the olfactory epithelium to its presynaptic terminal in the olfactory bulb. Thus, in both visual and olfactory sensory neurons, temporal control of signaling comes down to a balance between cyclic nucleotide synthesis and degradation. Interestingly, the detection of tastants and pheromones by GPCR-containing gustatory and vomeronasal sensory neurons, respectively, proceeds through a somewhat different signaling pathway involving G-protein-mediated activation of phospholipase $\mathrm{C}$, which promotes hydrolysis of membrane phospholipids to generate second messengers (such as diacylglycerols, inositol phosphates, and polyunsaturated fatty acids) and thereby triggers calcium release from intracellular stores (Fig. 1C). These actions promote the opening of excitatory TRP ion channels, leading to depolarization and neurotransmitter release (Chandrashekar et al. 2006).

The same principles that underlie signal amplification-namely, the involvement of multiple sequential steps in a transduction pathway-endow metabotropic (i.e., GPCR) systems with a great capacity for adaptation and other forms of signal modulation. Here, again, the most detailed analysis has been performed in the visual system. The retina faces the daunting task of discriminating luminance changes on a timescale of tens of milliseconds and under conditions as disparate as sunny afternoons and moonless nights, in which background light intensity varies by more than six orders of magnitude. These challenges are met, in part, through negative feedback mechanisms in the photoreceptor outer segment that terminate signaling and/ or reset the baseline in the presence of a persistent stimulus. Although first delineated in studies of rod phototransduction, these feedback mechanisms are now known to be more-or-less generic to many GPCR signaling pathways (DeWire et al. 2007; Moore et al. 2007). The most receptorproximal signal termination mechanism involves phosphorylation of activated receptors by specific serine/threonine kinases, such as rhodopsin kinase, a member of the G-protein receptor kinase (GRK) family, at several residues in the long carboxy-terminal tail of the receptor on a timescale of tens of milliseconds (Arshavsky et al. 2002). Once phosphorylated, the receptor is capped by the inhibitory protein arrestin, which blocks subsequent G-protein activation. In hormone and neurotransmitter receptor systems, arrestin binding also facilitates receptor endocytosis and recycling. In contrast, in the photoreceptor outer segment, rhodopsin remains stably localized to the disc membrane. Rhodopsin is recycled to its dark state by the combination of dephosphorylation and exchange of the photoisomerized all-trans retinal chromophore for a new molecule of 11-cis retinal, reactions that occur on a timescale of minutes (Arshavsky et al. 2002; Yau and Hardie 2009).

The time course of photoreceptor signal termination is also shaped by the accelerated hydrolysis of G-proteinbound GTP via an allosteric interaction between the regulator of G-protein signaling (RGS) family member RGS9 and the $\alpha$-subunit of the photoreceptor G protein, transducin (Krispel et al. 2006). RGS-modulated signal termination plays an analogous role in primary olfactory sensory neurons in Caenorhabditis elegans (Ferkey et al. 2007). RGS-dependent enhancement of GTP hydrolysis is an ancient and evolutionarily conserved mechanism that accelerates signal termination across a wide variety of heterotrimeric and small G-protein signaling systems in organisms as diverse as yeast and man (Dohlman and Thorner 1997; Ross and Wilkie 2000; Netzel and Hepler 2006). In vertebrate photoreceptors, a third mechanism for activitydependent feedback involves a light-dependent decline in intracellular calcium levels, which leads to the allosteric activation of guanylate cyclase, the enzyme that synthesizes cGMP, by small calcium-binding proteins termed guanylate-cyclase-activating proteins (GCAPs) (Yau 1991; Yau and Hardie 2009). In other GPCR signaling systems, calcium feedback acts on a wide variety of cellular effectors.

Ion channels are distinguished from multicomponent signaling cascades by the rapidity of their response, enabling ionotropic receptors to convert stimuli into neuronal depolarization on a millisecond timescale, as compared with tens or hundreds of milliseconds for most metabotropic systems (Fig. 2). This is especially relevant when the physiological timescale of stimulus presentation is rap$\mathrm{id}$, as in acoustic signals. In this case, sound pressure waves with vibration frequencies on the order of several thousand cycles per second (or, for bats, up to 100,000 cycles per second) are detected by mechanically gated ion channels with open probabilities that are modulated by the rapid back-and-forth movements of a tightly interconnected set of microvilli, the stereociliary bundle (Fig. 1D). In this system, adaptation is effected by dynamic changes in the tension in the elastic elements that gate the channels.

Ion channels also have a great capacity for signal integration and gain control. This phenomenon is nicely 
Downloaded from http://cshperspectives.cshlp.org/ on April 26, 2023 - Published by Cold Spring Harbor Laboratory Press D. Julius and J. Nathans
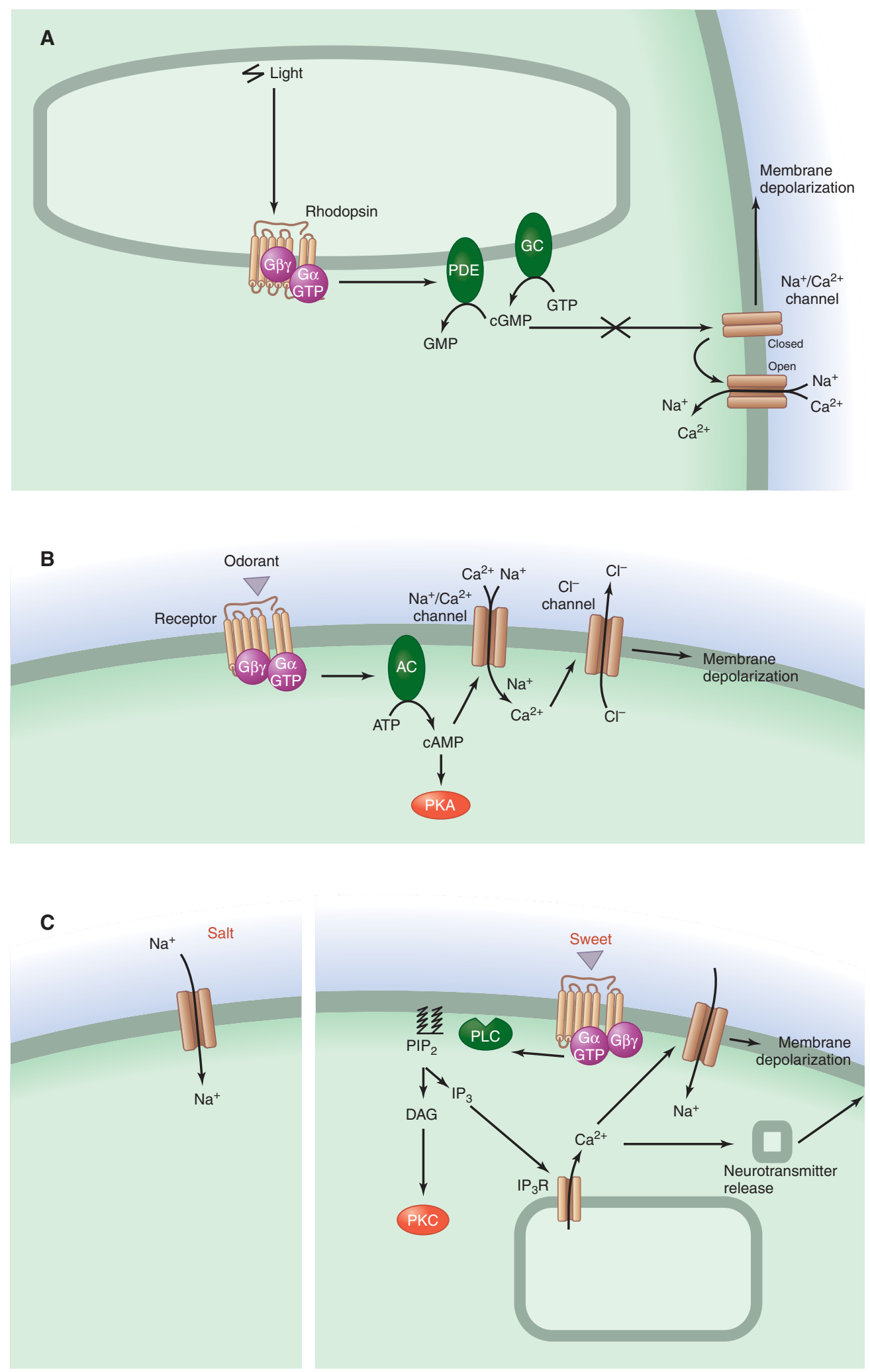

Figure 1. (See facing page for legend.) 
D

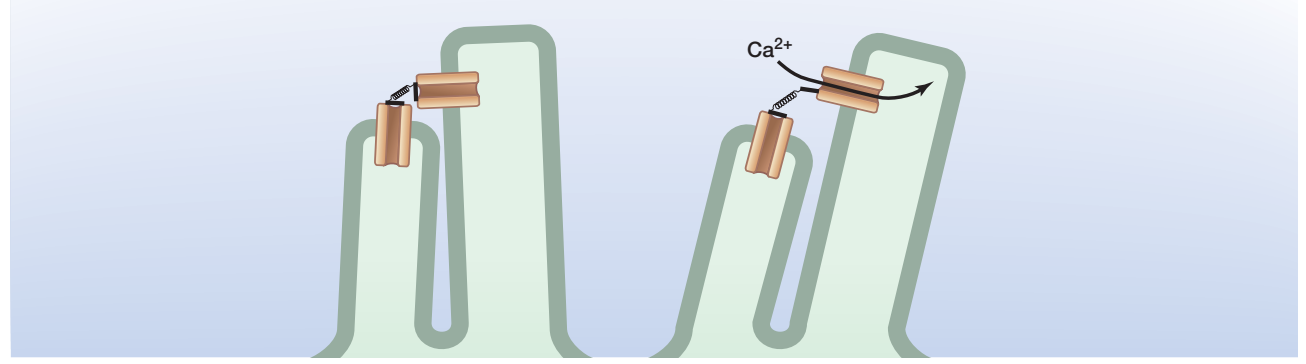

E

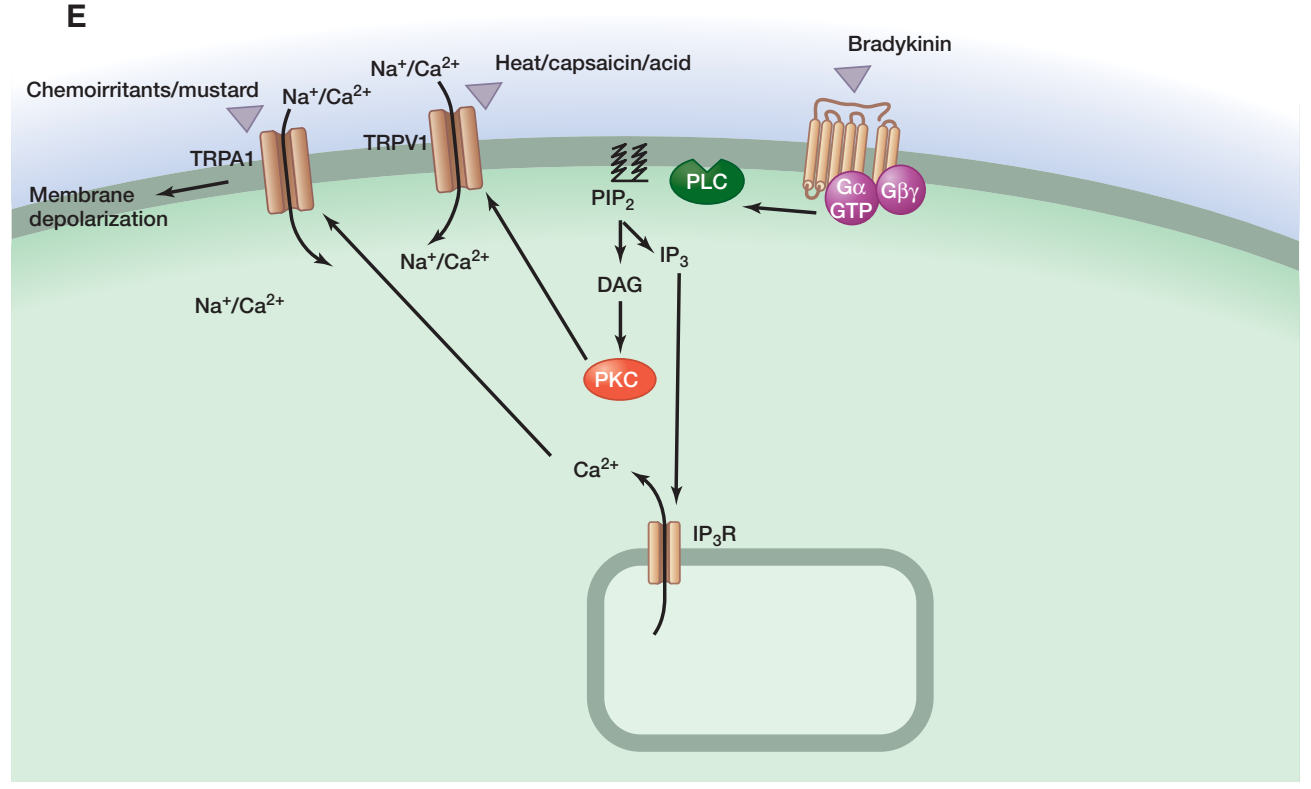

Figure 1. Comparison of sensory signaling systems for vision, olfaction, hearing and balance, taste, and pain/thermosensation. The events underlying signal transduction are shown schematically for $(A)$ rod and cone photoreception; $(B)$ olfaction in the main olfactory epithelium; $(C)$ salt $(l e f t)$ and sweet (right) taste; $(D)$ hearing and balance; and $(E)$ pain/thermosensation. Schematics $A-E$ refer to vertebrates. The final step in olfactory signaling consists of the calcium-dependent opening of anion channel TMEM16B, although recent work suggests that the resulting anion current plays only a minor role in olfactory signal transduction (Billig et al. 2011). For pain/thermosensation mediated by TRPV1, the figure shows inflammatory agents (extracellular protons, bioactive lipids, peptides, and neurotrophins) acting to enhance channel opening either as direct allosteric modulators of TRPV1 or through second-messenger signaling pathways. In auditory and vestibular hair cell bundles, it is not known whether transduction channels reside at both ends or at only one end of the extracellular elastic elements (tip links); in panel $D$ the channels are shown at both ends.

illustrated in the somatosensory system, where the capsaicin- and heat-activated receptor TRPV1 is modulated by multiple components of the inflammatory milieu, including bioactive lipids, extracellular protons, neurotrophic factors, and inflammatory peptides (Fig. 1E). These agents enhance the sensitivity of TRPV1 to heat by functioning either directly as allosteric modulators of the channel or indirectly through metabotropic pathways that modulate TRPV1 channel function. These actions contribute to heightened pain sensitivity following tissue injury, such as sunburn, and constitute an important part of the pain pathway's protective function (Caterina and Julius 2001).

One outstanding question in sensory transduction concerns the molecular mechanisms used by cells to detect and 
D. Julius and J. Nathans

Table 1. Classes of sensory receptors

\begin{tabular}{|c|c|c|}
\hline Sensory modality ${ }^{a}$ & Receptor(s) & Transduction mechanism \\
\hline Vision & GPCRs & $\begin{array}{l}\text { G-protein/cGMP } \\
\text { phospho-diesterase/ } \\
\text { cGMP-gated ion channel }\end{array}$ \\
\hline Olfaction $^{\mathrm{b}}$ & GPCRs & $\begin{array}{l}\text { G-protein/adenylyl } \\
\text { cyclase/cAMP-gated ion } \\
\text { channel }\end{array}$ \\
\hline Hearing/balance & $\begin{array}{l}\text { Nonselective } \\
\text { cation } \\
\text { channel }\end{array}$ & $\begin{array}{l}\text { Direct gating by mechanical } \\
\text { force }\end{array}$ \\
\hline $\begin{array}{l}\text { Taste (sweet and } \\
\text { bitter) }\end{array}$ & GPCRs & G-protein/TRP channel \\
\hline Taste (sour) & Ion channel & Direct sensing of ion flux \\
\hline $\begin{array}{l}\text { Mechanosensation } \\
\text { (in bacteria) }\end{array}$ & Ion channel & Membrane stretch \\
\hline
\end{tabular}

${ }^{\mathrm{a}}$ Data are for vertebrates unless otherwise noted.

${ }^{\mathrm{b}}$ Data are for the main olfactory epithelium. A minority of olfactory sensory neurons appear to use transmembrane guanylate cyclases as receptors.

respond to mechanical stimuli (focal pressure, stretch, and osmotic challenge) (Gillespie and Walker 2001; Kung 2005). To date, this is best understood in prokaryotic systems, in which potentially lethal hypotonic shock leads to the activation of both small- and large-conductance cell surface mechanosensory channels, MscS and MscL, respectively, that equalize solute gradients by conducting anions, cations, and other small molecules relatively nonselectively. Reconstitution of purified MscS and MscL proteins in synthetic lipid bilayers has shown that these channels are intrinsically mechanosensitive, opening and closing in direct response to changes in lateral membrane pressure (Sukharev et al. 1994; Sukharev 2002; Vásquez et al. 2008; Kung et al. 2010).

A more complex model has been proposed for mechanosensory transduction in metazoan systems, based on genetic studies in C. elegans. Here, screens for touchinsensitive mutants have identified loci encoding microtubule-associated proteins as well as members of the amiloride-sensitive sodium channel family, arguing for the existence of a mechanosensory complex in which membrane stretch promotes channel opening via cytoskeletal changes (Chalfie 2009). In contrast to the single-component bacterial Msc system, this model has not yet been fully validated through functional reconstitution in heterologous systems. Genetic and physiologic studies in flies and mammals have identified several additional candidates for mechanotransducers, including members of the TRP and Piezo channel families. Whether these channels respond to mechanical stimuli directly, as in bacteria, or indirectly through membrane/cytoskeletal attachment, as in nematodes, remains to be determined.

\section{STRUCTURAL BASIS OF SENSORY RECEPTOR ACTIVATION}

Among eukaryotic sensory receptors, we currently know most about the structure of GPCRs and how they interact with ligands, G proteins, and arrestins. Much insight has been gleaned from studies of rhodopsin and the $\beta$-adrenergic and adenosine receptors, for which three-dimensional (3D) structures of active and inactive conformational states have recently been determined (Rosenbaum et al. 2009; Choe et al. 2011; Rasmussen et al. 2011; Standfuss et al. 2011; Xu et al. 2011). Crystallographic studies confirm that these receptors contain a membrane-embedded core of seven transmembrane $\alpha$-helices with amino- and carboxy-terminal tails facing outside and inside the cell,
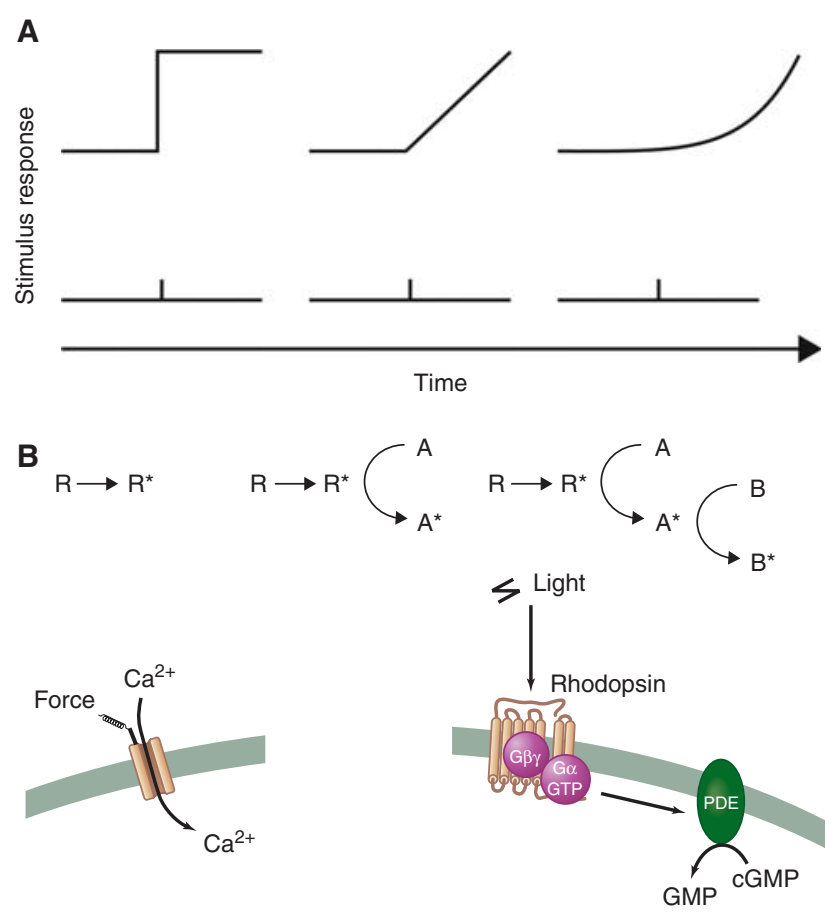

Figure 2. Schematic representation of temporal response profiles for single or multicomponent transduction systems. (A) Time course of stimulus-evoked responses for transduction systems consisting of zero, one, or two enzymatic stages of amplification. (B) For each system, the schematic diagram shows the flow of information in the transduction system, with $\mathrm{R}$ and $\mathrm{R}^{*}$ representing the sensory receptor molecule in the inactive and active states, respectively. (Left panel) Here, there are no transduction components beyond the receptor itself, as in the case of a sensory ion channel, where activation is nearly instantaneous. (Middle panel) Here, the active receptor functions as a catalyst and converts inactive molecules of A to their active derivatives $A^{*}$, which accumulate linearly with time following receptor activation. (Right panel) Here, the active derivative $\mathrm{A}^{*}$ functions as a catalyst to convert inactive molecules of $\mathrm{B}$ to their active derivatives $\mathrm{B}^{*}$, resulting in second-order response kinetics. The left panel represents a mechanosensory system, and the right panel represents vertebrate phototransduction, as diagrammed below. 
respectively. We note that that in the case of rhodopsin, the amino terminus faces the lumen of the outer segment disc, which is topologically equivalent to the outside of the cell.

Binding of low-molecular-weight agonists and antagonists to the $\beta$-adrenergic and adenosine receptors, or lightinduced isomerization of covalently bound retinal in rhodopsin, occurs within a pocket that is formed by four of the seven $\alpha$-helices and is located below the surface of the plasma membrane (Fig. 3A). Subtle agonist-induced structural changes within this pocket promote rotational movements in hinge regions of helices 5 and 6 that sit at the midpoint of the lipid bilayer. This motion, in turn, exposes a hydrophobic G-protein-binding site formed by loops linking the cytoplasmic ends of transmembrane domains 5, 6, and 7.

Crystallographic and molecular dynamics simulations suggest that interactions with both ligand and G protein are required to fully stabilize the activated conformation of some GPCRs. This is consistent with classic pharmacological observations showing that agonist affinities decrease substantially when the G-protein is released. Interestingly, the conformational equilibrium between inactive and active states differs among GPCRs. Some receptors, such as the $\beta 2$-adrenergic receptor, make occasional transitions to the activated state in the absence of ligand. In contrast, rhodopsin remains almost completely inactive in the absence of retinal isomerization, thereby maintaining the low level of dark noise that is characteristic of vertebrate rod phototransduction.

Much less is currently known about the tertiary structure of most ion channels that function as sensory receptors. Bacterial MscS and MscL mechanosensory channels are the exception: their crystal structures have been resolved to approximately $4 \AA$ resolution (Perozo and Rees 2003; Kung et al. 2010). These stretch-activated channels assume two rather different overall configurations. MscS is a homoheptameric channel in which the seven subunits are arranged around a central axis. The third transmembrane helix of each subunit lines the ion-conducting pore, whereas the other two helices form a cone-shaped outer shell that interacts with membrane lipids. MscL is a homopentameric channel in which each subunit has two transmembrane helices, one facing the ion pore and the other facing the lipid bilayer. Despite their distinct stoichiometries and architectures, MscS and MscL perform the same function of opening and closing in response to changes in lateral pressure or surface tension exerted by the surrounding lipid bilayer as it undergoes deformation. Structural and molecular dynamics simulation studies suggest that in response to membrane stretching, both channels undergo rotational and kinking movements of their transmembrane helices to open a central ion-conducting pore, much as an iris opens in an old-fashioned camera (Fig. 3B).
At present, structural insights into metazoan sensory channel function are limited. For TRP channels, progress is currently limited to high-resolution structures of small soluble domains and low-resolution $(\sim 20 \AA)$ structures of the intact channel derived from electron microscopic images (Malnic et al. 1999; Gaudet 2008; Li et al. 2011). How some TRP channels, such as TRPV1 and TRPM8, detect and respond to changes in ambient temperature remains an intriguing and unresolved question. Heterologous expression and in vitro proteoliposome reconstitution studies suggest that TRPV1 and TRPM8 are intrinsically temperature-sensitive, but whether gating in vivo involves channel-lipid interactions or association with other cellular factors remains uncertain. Mutational studies have implicated several channel domains as being important in temperature detection or specification of thermal activation thresholds, but the structural underpinnings of these processes have yet to be elucidated.

\section{THE LOGIC OF SENSORY CODING}

Sensory systems create an internal representation of the external world filtered through the molecular specificities of primary receptor proteins. Thus, the act of sensory coding can be conceptualized as an act of remapping: One multidimensional space (of sensory stimuli) is remapped onto another multidimensional space (of receptor cell responses). We focus here only on the representation of sensory stimuli at the level of the primary receptors, but note that the remapping process continues at each stage of sensory processing up to and including brain circuitry. For example, in the visual system, the distinct attributes of form, color, motion, and depth are extracted from the retinal image and processed in partially overlapping information streams in the visual cortex (Livingstone and Hubel 1988).

In bacteria, plants, and animals, light-sensing systems are based on the photoisomerization of a chromophore with a conjugated $\pi$-electron system: retinal or one of its derivatives in bacterial and animal rhodopsins (Fig. 4), and a tetrapyrrole in plant phytochromes. Although the energy difference between ground and excited electronic states is quantized, the receptor's absorbance spectrum (i.e., absorbance as a function of wavelength) appears as a relatively broad and approximately Gaussian curve. The breadth of the absorbance band arises from the large number of closely spaced vibrational energy states that are superimposed on the larger electronic energy gap (Abrahamson and Japar 1972). These broad absorbance bands permit a relatively small number of photoreceptors with partially overlapping spectral sensitivities to cover the biologically relevant region of the electromagnetic spectrum, the interval from near ultraviolet $(\sim 350 \mathrm{~nm})$ 
A

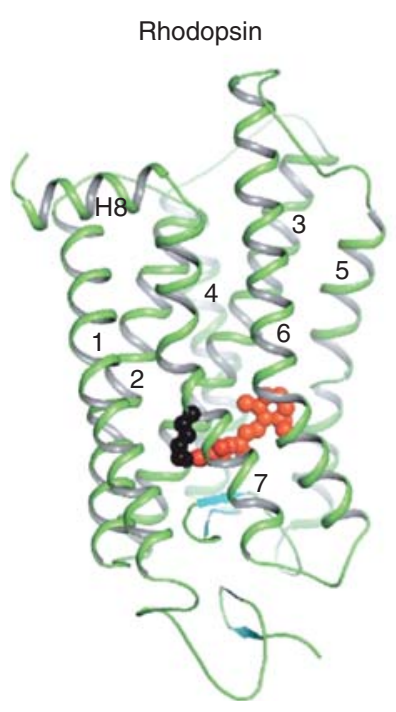

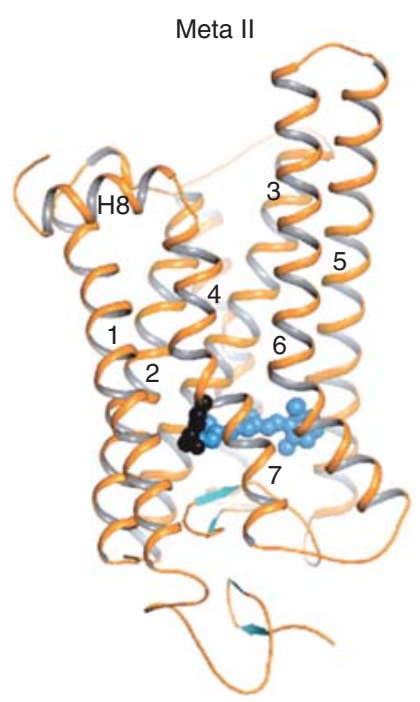

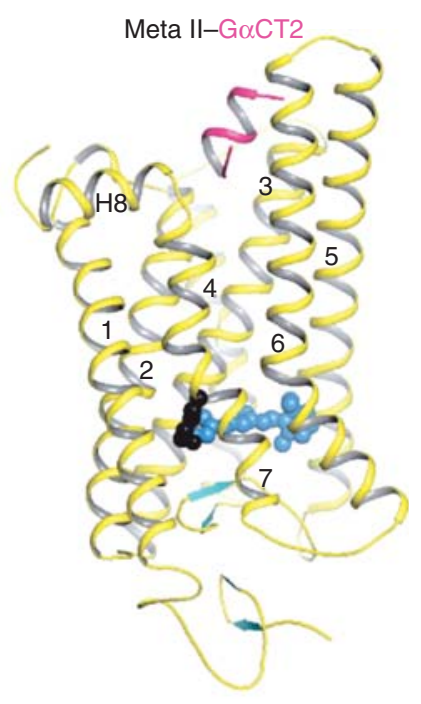

B
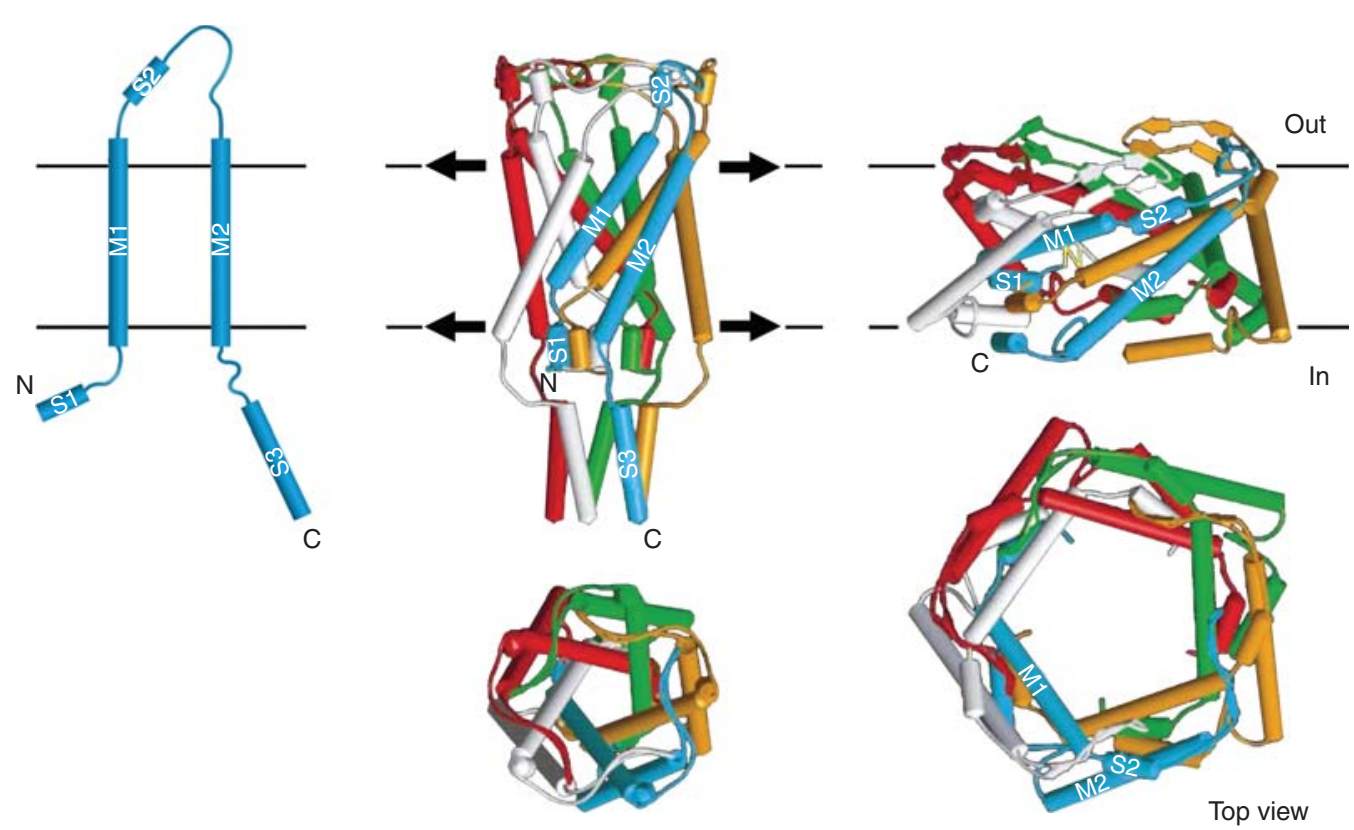

Figure 3. 3D structures of rhodopsin and a mechanically gated ion channel. (A) Ribbon diagram of rhodopsin in the inactive state with bound 11-cis-retinal (red spheres) compared with the light-activated Metarhodopsin II state containing all-trans-retinal (blue spheres) and Metarhodopsin II state in complex with a peptide ( pink) corresponding to the receptor-binding site on the $\mathrm{G} \alpha$ subunit of transducin. Rotation and elongation of light-activated retinal lead to a slight rotational tilt of transmembrane helices 5 and 6, thereby enlarging a crevice at the cytoplasmic side of the receptor in which Go can dock (Choe et al. 2011). (B) Bacterial mechanosensory ion channel, MscL, showing transmembrane topology of a monomer (top left) and the assembled pentameric channel complex (top middle). Membrane stretch and consequent changes in tension at the membrane-protein interface produce structural rearrangements that result in compression of the channel and expansion of the central ion permeation pore, as depicted in the side and top views (Kung 2005). 
A
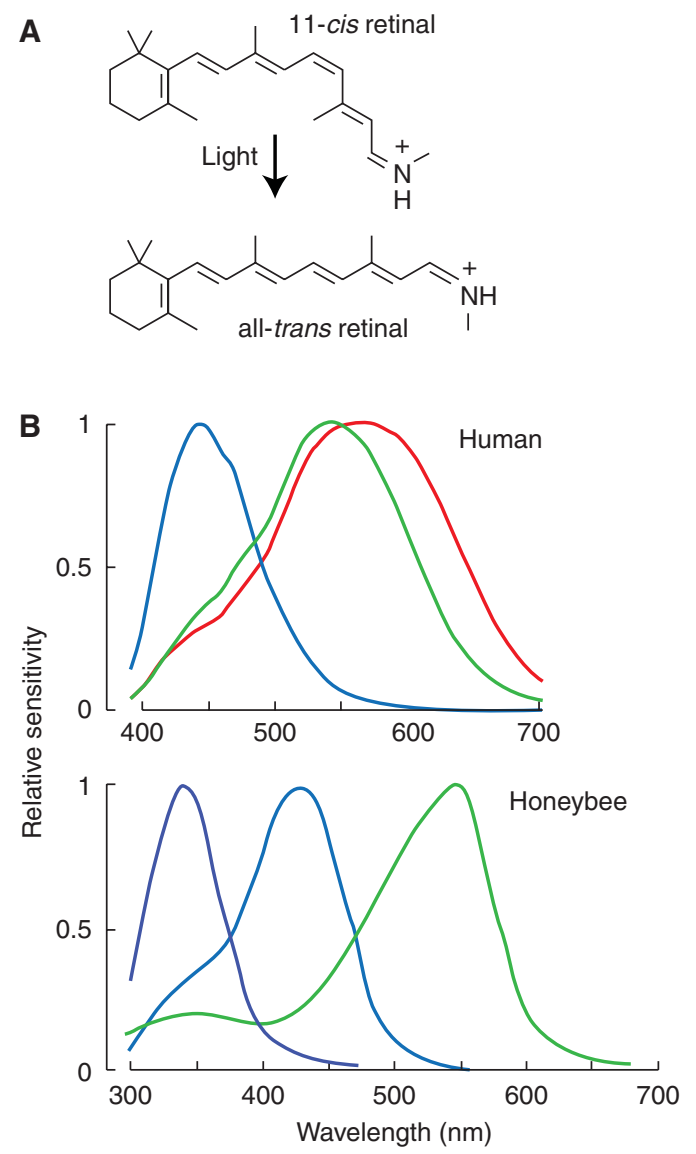

Figure 4. Color vision in humans and honeybees. $(A)$ Photoisomerization of retinal from 11-cis to all-trans, the photochemical event that initiates receptor activation in vertebrate and invertebrate photoreceptors. (B) Spectral sensitivities of human cone photoreceptors and honeybee rhabdomeric photoreceptors. (Adapted from Osorio and Vorobyev 2008; reprinted, with permission, from Elsevier (C) 2008.)

to far red $(650 \mathrm{~nm})$. In humans, there are five classes of light receptors: cone photoreceptors have sensitivity maxima of $\sim 440 \mathrm{~nm}, \sim 530 \mathrm{~nm}$, and $\sim 560 \mathrm{~nm}$; rod photoreceptors have sensitivity maxima of $\sim 500 \mathrm{~nm}$; and intrinsically photosensitive retinal ganglion cells - which mediate pupil constriction and light entrainment of circadian rhythmsexpress a highly divergent photoreceptor protein, melanopsin, that confers a sensitivity maximum of $\sim 480 \mathrm{~nm}$. The differential excitation of the three cone pigments provides information about the wavelength composition of a stimulus, a process that we recognize as color vision (Fig. 4).

The strategy of overlapping spectral sensitivities was first suggested by Thomas Young in a remarkably prescient passage in his 1801 Bakerian Lecture before the Royal Society:

As it is almost impossible to conceive each sensitive point of the retina to contain an infinite number of particles (receptors), each capable of vibrating in perfect unison with every possible undulation (frequency), it becomes necessary to suppose the number limited ... and that each particle is capable of being put in motion more or less forcibly by undulations differing less or more from perfect unison (Young 1802).

Following Young's argument, we could measure light intensity as a function of wavelength from a particular location in a scene, sampling from $400 \mathrm{~nm}$ to $650 \mathrm{~nm}$ in $1-\mathrm{nm}$ steps, and then represent the data by a single point in a 250-dimensional space. Young correctly surmised that the visual system remaps this high-dimensional stimulus space onto a lower-dimensional space of receptor activities.

One inevitable result of such remapping is that some pairs of points that reside at distinct locations in the higherdimensional stimulus space will reside at indistinguishably close locations in the lower-dimensional receptor space. For color vision based on only three or four classes of receptors, surprisingly little information is lost relative to that which could be extracted by a larger ensemble of receptors. The reason for this is that the biological pigments that dominate natural scenes-like the chromophores of photoreceptors-have broad and relatively smooth bell-shaped absorbance curves. (Recall that the visual stimulus, i.e., the light reflected from an object, is proportional to the reciprocal of the absorbance spectrum.) In other words, the information content in the absorbance spectra of biomolecules is contained largely in their low-frequency components, with the word "frequency" referring not to a particular wavelength of light but to a Fourier decomposition of the curve of reflectance versus wavelength (Maloney 1986).

A simpler transformation between stimulus and response spaces is effected by taste receptors (Yarmolinsky et al. 2009). In mammals, sweet, umami (amino acid), and bitter tastants stimulate GPCRs, whereas sodium and hydrogen ions (i.e., salty and acidic modalities) are detected by members of the amiloride-sensitive and TRP ion channel families, respectively. Two classes of specialized taste cells express low-affinity GPCRs to detect common nutrients: T1R1-T1R3 heterodimers detect L-amino acids, and T1R2-T1R3 heterodimers detect sugars. The relatively low ligand-receptor affinities (in the millimolar range) are appropriate given the organism's interest in identifying quantities of ligand sufficient for its nutritional needs. The umami and sweet taste receptors are of additional interest because, together with the gamma-aminobutyric acid (GABA)-B receptor, they represent the best-validated examples in which receptor dimerization is required for G-protein signaling (Milligan 2009).

A distinct class of taste receptors coexpress a mixture of about 30 high-affinity GPCRs (T2Rs) that recognize a broad array of bitter compounds, many of which are plantderived toxins. The uniformly bitter sensation elicited 
by diverse T2R ligands attests to the compression of a multidimensional chemical stimulus space onto a single psychophysical dimension of bitterness-a logical feature given that the only behavioral output is aversion. This arrangement sacrifices discriminatory power, but it enables an organism to determine whether a substance is nutritionally beneficial (eliciting an attractive response) or potentially toxic (eliciting an aversive response).

Another apparently simple transformation between stimulus and response spaces is seen in mammalian thermosensation (Lumpkin and Caterina 2007). In this case, a scalar quantity, temperature, is detected by largely distinct sets of sensory neurons, each of which expresses one type of temperature-gated TRP channel. The critical features of this system are (1) the polarity of the response-channel opening that is either heat-activated (TRPV1) or cold-activated (TRPM8); (2) the temperature at the midpoint of the S-shaped stimulus-response curve; and (3) the steepness of the stimulus-response curve. The last of these features may reflect cooperative interactions among TRP channel subunits that line a central pore. For each class of thermosensory neurons, the monotonic mapping of stimulus temperature to response shows systematic compressions and expansions along the temperature axis, with maximal sensitivity to small changes in temperature occurring, as one would expect, in the steepest region of the receptor's stimulus-response curve. For mammals, the intervals of maximal sensitivity flank normal peripheral body temperatures: $\sim 15^{\circ} \mathrm{C}$ to $\sim 25^{\circ} \mathrm{C}$ for cold receptors and $\sim 35^{\circ} \mathrm{C}$ to $\sim 50^{\circ} \mathrm{C}$ for heat receptors (Iggo 1982). In keeping with this pattern, the temperature of the half-maximal response of TRPM8 orthologs differs among species and correlates with core body temperature (Myers et al. 2009).

In reality, the situation is more complex than the preceding paragraph indicates because, as noted above, thermosensory neurons integrate additional stimulus dimensions by virtue of the sensitivity of various TRP channels to chemical ligands and by the sensitizing action of inflammatory mediators at the cellular level (Basbaum et al. 2009). Many TRP channel activators are plant-derived compounds that provoke a sensation of irritation or burning pain. Primary afferent neurons coexpressing capsaicin (TRPV1) and wasabi (TRPA1) receptors are dually sensitive to heat and electrophilic irritants, a mixed-modality arrangement wherein chemical irritants and inflammatory agents excite heat-sensitive fibers to produce thermal hyperalgesia (increased sensitivity to pain). This phenomenon of cross-modality signaling appears as a distinctive feature of somatosensation, presumably reflecting the protective function of the pain pathway. Thus, thermosensory neurons provide the organism with a sensory space in which noxious chemical and thermal stimuli are integrated with tissue injury and inflammation to yield gradations of two relatively simple sensations, pain and temperature.

Olfactory systems illustrate the most complex stimulus-response relationships. This complexity reflects the extraordinary diversity of chemical space and the large number of distinct odorant receptors $(\sim 100$ to $\sim 1000)$ expressed in vertebrates and invertebrates (Su et al. 2009). The most naive mapping would assign each odorant an independent axis in stimulus space and each receptor an independent axis in response space. Even if the two spaces are compressed by combining the attributes of related compounds and related receptors into a smaller number of axes-a method referred to as principal component analysis-the dimensionality of each space remains extremely large.

Systematic analyses in which a transgenic receptor is expressed in a single neuron from which the endogenous receptor has been eliminated (the "empty neuron" technique) have delineated odorant responses for the entire olfactory repertoire in fruit flies and other insects (Hallem and Carlson 2006; Carey et al. 2010). Similarly, taking advantage of the one-receptor-one-neuron relationship in the main olfactory epithelium of mammals, researchers have used calcium imaging during odorant exposure followed by single-cell PCR to delineate basic patterns of odorant receptor specificities (Malnic et al. 1999). Several fundamental observations have emerged from these studies (Malnic et al. 1999; Hallem et al. 2004; Hallem and Carlson 2006; Carey et al. 2010; Wang et al. 2010): First, individual odorants typically activate more than one receptor, and, conversely, individual receptors are typically activated by more than one odorant. Second, receptors differ in the breadth of their odorant responses: Some receptors are activated by a small number of odorants, whereas others are activated by a larger number of odorants, often with related chemical structures. Third, both the level of receptor activation and the number of classes of activated receptors increase with increasing odorant concentration. Organisms face the further challenge of interpreting mixtures of odorants, and for this task, additional identifying information can be obtained based on antagonistic interactions between pairs of odorants and on odorant-specific temporal dynamics of receptor responses (Hallem et al. 2004; Oka et al. 2004, 2009; DasGupta and Wadell 2008; Su et al. 2011).

\section{EVOLUTION AND VARIATION}

The strongest selective pressure for optimal performance in sensory systems occurs when the stimulus affects behaviors most directly related to Darwinian selection: feeding, mating, and avoiding death from predation, poisoning, and so on. Conversely, sensory systems that gather information 
that is of little or no utility will disappear over time, a process recognizable by the loss or inactivation of their associated gene sequences. As the following examples illustrate, these considerations inform any comparisons among species of the performance characteristics of sensory systems.

Variations among different types of photoreceptors, both within and between species, beautifully illustrate the evolution of sensory system performance to fit diverse ecological needs (Yau and Hardie 2009). For example, different signal-to-noise ratios are apparent in rod-mediated night vision (where the ratio must be high) compared with conemediated daytime vision (where the ratio can be lower). The rod visual pigment, rhodopsin, has a half-life for spontaneous activation at $37^{\circ} \mathrm{C}$ of $\sim 400 \mathrm{yr}$, corresponding to an energy barrier of $\sim 22 \mathrm{kcal} / \mathrm{mol}$ for thermal isomerization of the 11-cis retinal chromophore (Baylor et al. 1980). In mammalian rods, which have $4 \times 10^{7}$ rhodopsins per cell, this works out to only approximately one spontaneous activation event per minute per rod. This very low level of receptor noise represents a critical performance feature that sets the absolute sensitivity of dim light vision (Hecht et al. 1942; Baylor et al. 1980). In contrast, mammalian cones operate at light levels that are several orders of magnitude higher than the rod operating range, and cones are correspondingly several orders of magnitude noisier than rods (Schnapf et al. 1990; Schneeweis and Schnapf 1999).

Visual pigment spectral sensitivity is one of the most intensively studied systems in which sensory receptor evolution has been explored at the molecular, organismal, and ecological levels. In the ocean, chlorophyll and other biomolecules in photosynthetic microorganisms selectively deplete longer-wavelength sunlight, and, as a result, there is a corresponding blueshift in the visual pigment spectral sensitivities of fish that live at greater ocean depths (Lythgoe 1979). Similarly, dolphin rhodopsin and the dolphin long-wavelength cone pigment are blueshifted relative to their terrestrial counterparts as an adaptation to the aquatic environment (Fasick et al. 1998; Fasick and Robinson 2000). At extreme depths, where little sunlight penetrates, visual pigment spectral sensitivities are under entirely different selective pressures: Bioluminescence permits communication among organisms of the same species, and visual pigments are tuned to the emitting wavelengths, in some cases at the far-red end of the spectrum (Douglas et al. 1998).

Visual pigment spectral tuning has also been studied in relation to discrimination among natural objects that are behaviorally relevant (Osorio and Vorobyev 2008). Comparing the color space defined by honeybee rhabdomeric photoreceptors, which have sensitivity maxima at $\sim 350$, $\sim 425$, and $\sim 550 \mathrm{~nm}$, with that defined by human cone photoreceptors, which have sensitivity maxima of $\sim 440$, $\sim 530$, and $\sim 560 \mathrm{~nm}$ (representative of Old World primate cone sensitivities) (Fig. 4), reveals a wider dispersion of floral hues in honeybee color space compared with primate color space (Fig. 5). This pattern supports the general idea that color vision in pollinator species such as honeybees, butterflies, and hummingbirds coevolved with floral pigments to enhance discrimination among floral species, an arrangement that enhances both feeding and pollination. Similarly, the surface hues of fruits that are consumed by primates occupy a wider swath of primate color space compared with honeybee color space (Fig. 5), a pattern that suggests that primate trichromacy may have coevolved with fruit coloration to enhance both fruit consumption and seed dispersal (Regan et al. 2001). In particular, yellow, orange, or red fruit is readily detected against a background of dappled green foliage if an animal compares the extents of excitation of a pair of visual pigments in the 500$600-\mathrm{nm}$ region of the spectrum, as nearly all Old World and some New World primates can (Mollon 1989; Regan et al. 2001). Such discrimination is difficult with the single longer-wavelength-sensitive pigment typical of non-primate mammals. A chromatic discrimination task similar to this one is the basis of the Ishihara test for color vision deficiency in humans.
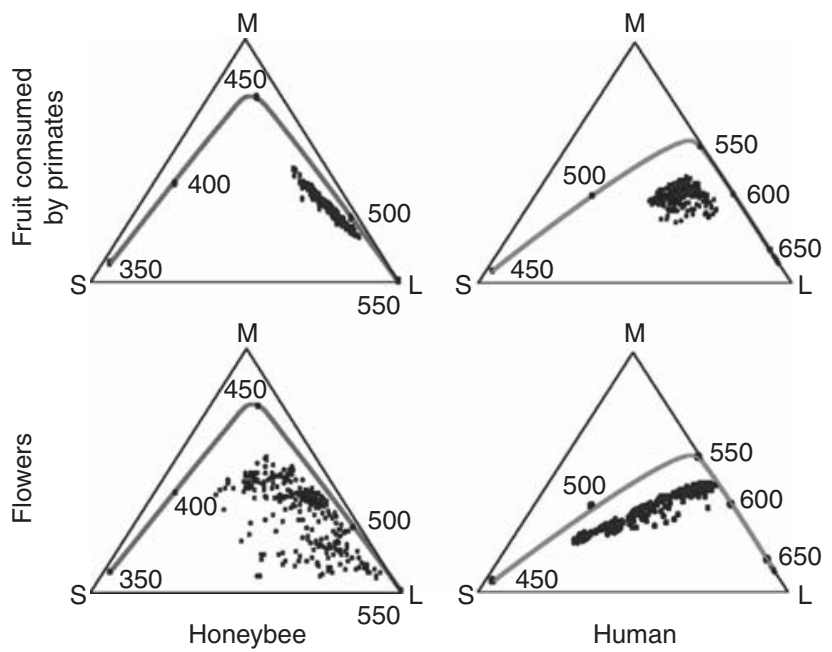

Figure 5. Chromaticity diagrams for humans and honeybees. The triangles represent a plane within a $3 \mathrm{D}$ receptor space, with each vertex corresponding to the point at which the plane intersects an axis representing the degree of excitation of one receptor type. (S) Shortwavelength receptor axis; $(\mathrm{M})$ medium-wavelength receptor axis; (L) long-wavelength receptor axis. The small black circles within the triangles represent the chromaticities of a set of fruits that are consumed by primates (upper panels) or a set of flower petals (lower panels). The line within each chromaticity diagrams represents the locus of spectrally pure lights, with black circles and the adjacent numbers marking steps of $50 \mathrm{~nm}$. (Adapted from Osorio and Vorobyev 2008; reprinted, with permission, from Elsevier (C) 2008.) 
Fruit flies and mosquitoes provide an analogous instance of species-specific differences in the patterning of salient odorants in olfactory receptor space. Drosophila melanogaster feeds on ripe or rotting fruit and appears to be especially good at discriminating among esters, the dominant volatiles emitted by fruit (Su et al. 2009; Carey et al. 2010). In contrast, Anopheles gambiae feeds on human blood and is better at discriminating aromatics, including several that are characteristic of humans (Carey et al. 2010). High salience is also seen in the heterodimeric carbon dioxide receptors of Drosophila and Anopheles. In Drosophila, this odorant represents a stress signal, whereas in Anopheles, it is one of the chemotactic signals used to identify a human host (Jones et al. 2007; Lu et al. 2007). Finally, receptors specific for within-species olfactory communication, most especially in the context of pheromones, have been identified in both vertebrates and invertebrates (Touhara and Vosshall 2009). In Drosophila, cis-vaccenyl acetate (cVA) is produced by males, increases female receptivity, and then-upon transfer to the female partner during mating-decreases female attractiveness to other males. Interestingly, the responses to cVA are mediated through at least two odorant receptors (Or67d and Or65a), a twotransmembrane-domain coreceptor (SNMP), and a soluble odorant-binding protein (LUSH) (Vosshall 2008).

As noted in the discussion above on primate color vision and fruit consumption, an immobile plant has much to gain if it can encourage animal foragers to help spread its seeds. Avian foragers present the best opportunity for widespread seed dispersal, and, therefore, one might expect that plants and the birds that disperse their seeds would have coevolved a strategy that discourages competition from less desirable foragers such as mammals. A striking example of this phenomenon is seen in the insensitivity of the avian vanilloid thermosensory channel (TRPV1) to activation by capsaicin, which is the source of the painfully "hot" sensation elicited by chili peppers (Jordt and Julius 2002). Capsaicin thus appears to selectively repel mammals by activating their temperature/ pain receptors, thereby preserving the pepper seeds for consumption and transport by birds. The avoidance or non-avoidance of food constitutes a major point of intersection between animal and plant ecologies. In this respect, it is interesting that the vertebrate bitter receptor (T2R) gene repertoire-which represents a sum of all undesirable edible compounds, many of which are plant-derived-is evolving rapidly (Dong et al. 2009).

The most extreme change in sensory signaling is a complete loss of receptor function. In the genomes of the bushbaby (Otolemur crassicaudatus) and owl monkey (Aotus trivirgatus) - primates with predominantly nocturnal lifestyles-the shortwave-sensitive cone pigment gene has decayed into a pseudogene, leaving only a single class of longer-wavelength cones to mediate daytime vision, with no possibility of color vision (Jacobs et al. 1996; Kawamura and Kubotera 2004). Similarly, in humans, all of the sequences coding for vomeronasal receptors of the V2R class, which mediate pheromone sensing in rodents, are pseudogenes (Touhara and Vosshall 2009). Among mammalian genes that encode the principal receptors of the main olfactory epithelium, the fraction that are pseudogenes ranges from $\sim 15 \%$ to $\sim 80 \%$, depending on the species (Niimura and Nei 2007; Niimura 2009; Touhara and Vosshall 2009). In dolphins, all genes encoding class II receptors of the main olfactory epithelium, which are mostly specialized for volatile hydrophobic ligands, appear to be inactivated by mutation (Freitag et al. 1998; Niimura 2009).

Any discussion of sensory signaling would be incomplete without considering the evolution of specialized anatomic structures that facilitate sensory function. The frequency-dependent conversion of sound pressure waves to localized basilar membrane distortions in the cochlea represents a dramatic example of these auxiliary structures in action. This micro-mechanical system is remarkably sensitive: the threshold for detecting basilar membrane displacement is $<1 \mathrm{~nm}$ (Johnstone et al. 1986). A larger-scale anatomic specialization is the increase in head width in hammerhead sharks. The great distance between left and right nasal openings, together with the evolution of olfactory receptor neurons that have sub-nanomolar affinities for amino acids, allows the hammerhead to sense shallow concentration gradients of dilute amino acids by comparing the excitation of left and right olfactory sensory epithelia (Tricas et al. 2009; Gardiner and Atema 2010). This spatial differencing strategy is the olfactory analog of binaural sound localization in mammals.

A particularly striking instance of anatomic specialization is seen in the pit organs of vipers such as rattlesnakes. Stretched across the pit is an extremely thin tissue that is densely innervated by thermosensory fibers. The fibers express a TRP channel that senses the minute increase in temperature evoked by infrared radiation from a nearby warm-blooded animal (Gracheva et al. 2010). The low body temperature of the viper relative to its prey and the small heat capacity of the sensory tissue are important for optimal pit organ function. Recent calculations suggest that the sensory fibers of the pit organ can respond to temperature changes as small as $0.001^{\circ} \mathrm{C}$ (Bakken and Krochmal 2007).

\section{CONCLUDING REMARKS}

The sensory receptors and signaling systems described here represent only a small sampling of the many that have been 
investigated. Because of space limitations, we have not discussed plant sensory systems, and we have only briefly touched on microbial systems. Even with this limited sampling, the diversity of sensory systems is striking, and it is evident that each lifestyle and ecological niche is accompanied by a distinctive set of adaptations in sensory system structure and function.

Over the past 30 years, the identities and primary structures of most of the major classes of vertebrate sensory receptor proteins have been defined. The one exception is the mechanosensory channels in the auditory and vestibular system, which remain enigmatic. The signaling cascades downstream from GPCR-type sensory receptors have also been largely defined. In vertebrate photoreception, the best studied of all GPCR signaling cascades, it is likely that all of the components involved in signaling and adaptation are now known. In less experimentally accessible systems, such as the taste and vomeronasal systems, additional signaling components remain to be identified, and the interactions between signal activation pathways and feedback loops are still incompletely understood.

A full molecular understanding of sensory receptor function requires the 3D structures of receptors and signaling components in their various active and inactive conformations, and, in some cases, in complex with each other. This has been achieved for rhodopsin, transducin, and the bacterial MscL mechanosensory channel, and it is an area of active investigation for other classes of sensory receptors and their downstream effectors. Structural studies can be expected to play a critical role in elucidating the molecular basis of receptor-ligand specificity in chemosensory systems.

A further challenge in the field of sensory biology comes from the need to diagnose and treat diseases that affect sensory signaling, including those associated with chronic pain or the loss of vision or hearing. Understanding sensory signaling at the molecular and cellular levels will inform these clinical investigations and will continue to be one of nature's grand scientific challenges for biologists, chemists, physicists, and engineers.

\section{REFERENCES}

Abrahamson EW, Japar SM. 1972. Principles of the interaction of light and matter. In Handbook of sensory physiology. VII/1: Photochemistry of vision (ed. Dartnall HJA), pp. 1-32. Springer-Verlag, Berlin.

Arshavsky VY, Lamb TD, Pugh EN. 2002. G proteins and phototransduction. Annu Rev Physiol 64: 153-187.

Bakken GS, Krochmal AR. 2007. The imaging properties and sensitivity of the facial pit of pitvipers as determined by optical and heat-transfer analysis. J Exp Biol 210: 2801-2810.

Basbaum AI, Bautista DM, Scherrer G, Julius D. 2009. Cellular and molecular mechanisms of pain. Cell 139: 267-284.

Baylor DA, Matthews G, Yau KW. 1980. Two components of electrical dark noise in toad retinal rod outer segments. J Physiol 309: 591-621.
Benton R, Vannice KS, Gomez-Diaz C, Vosshall LB. 2009. Variant ionotropic glutamate receptors as chemosensory receptors in Drosophila. Cell 136: $149-162$.

Billig GM, Pál B, Fidzinski P, Jentsch TJ. 2011. $\mathrm{Ca}^{2+}$-activated $\mathrm{Cl}^{-}$currents are dispensable for olfaction. Nat Neurosci 14: 763-769.

Campbell AL, Naik RR, Sowards L, Stone MO. 2002. Biological infrared imaging and sensing. Micron 33: 211-225.

Carey AF, Wang G, Su CY, Zwiebel LJ, Carlson JR. 2010. Odorant reception in the malaria mosquito Anopheles gambiae. Nature 464: 66-71.

Catania KC. 2005. Star-nosed moles. Curr Biol 15: R863-R864.

Caterina MJ, Julius D. 2001. The vanilloid receptor: A molecular gateway to the pain pathway. Annu Rev Neurosci 24: 487-517.

Chalfie M. 2009. Neurosensory mechanotransduction. Nat Rev Mol Cell Biol 10: 44-52.

Chandrashekar J, Hoon MA, Ryba NJ, Zuker CS. 2006. The receptors and cells for mammalian taste. Nature 444: 288-294.

Choe HW, Kim YJ, Park JH, Morizumi T, Pai EF, Krauss N, Hofmann KP, Scheerer P, Ernst OP. 2011. Crystal structure of metarhodopsin. II. Nature 471: 651-655.

DasGupta S, Wadell S. 2008. Learned odor discrimination in Drosophila without combinatorial odor maps in the antennal lobe. Curr Biol 18: $1668-1674$

DeWire SM, Ahn S, Lefkowitz RJ, Shenoy SK. 2007. $\beta$-Arrestins and cell signaling. Annu Rev Physiol 69: 483-510.

Dohlman HG, Thorner J. 1997. RGS proteins and signaling by heterotrimeric G proteins. J Biol Chem 272: 3871-3874.

Dong D, Jones G, Zhang S. 2009. Dynamic evolution of bitter taste receptor genes in vertebrates. BMC Evol Biol 9: 12.

Douglas RH, Partridge JC, Marshall NJ. 1998. The eyes of deep-sea fish. I: Lens pigmentation, tapeta and visual pigments. Prog Retin Eye Res 17: 597-636.

Fasick JI, Cronin TW, Hunt DM, Robinson PR. 1998. The visual pigments of the bottlenose dolphin (Tursiops truncatus). Vis Neurosci 15: $643-651$.

Fasick JI, Robinson PR. 2000. Spectral-tuning mechanisms of marine mammal rhodopsins and correlations with foraging depth. Vis Neurosci 17: 781-788.

Ferkey DM, Hyde R, Haspel G, Dionne HM, Hess HA, Suzuki H, Schafer WR, Koelle MR, Hart AC. 2007. C. elegans G protein regulator RGS-3 controls sensitivity to sensory stimuli. Neuron 53: 39-52.

Freitag J, Ludwig G, Andreini I, Rössler P, Breer H. 1998. Olfactory receptors in aquatic and terrestrial vertebrates. J Comp Physiol A 183: 635650 .

Gardiner JM, Atema J. 2010. The function of bilateral odor arrival time differences in olfactory orientation of sharks. Curr Biol 20: 1187-1191.

Gaudet R. 2008. TRP channels entering the structural era. J Physiol 586: $3565-3575$

Gillespie PG, Walker RG. 2001. Molecular basis of mechanosensory transduction. Nature 413: 194-202.

Gracheva EO, Ingolia NT, Kelly YM, Cordero-Morales JF, Hollopeter G, Chesler AT, Sánchez EE, Perez JC, Weissman JS, Julius D. 2010. Molecular basis of infrared detection by snakes. Nature 464: 1006-1011.

Hallem EA, Ho MG, Carlson JR. 2004. The molecular basis of odor coding in the Drosophila antenna. Cell 117: 965-979.

Hallem EA, Carlson JR. 2006. Coding of odors by a receptor repertoire. Cell 125: 143-160.

Hecht S, Schlaer S, Pirenne MH. 1942. Energy, quanta, and vision. J Gen Physiol 25: 819-840.

Henrik-Heldin C, Evans R, Gutkind S. 2012. Cold Spring Harb Perspect Biol (in press).

Iggo A. 1982. Cutaneous sensory mechanisms. In The senses (ed. Barlow HB, Mollon JD), pp. 369-408. Cambridge University Press, Cambridge.

Jacobs GH, Neitz M, Neitz J. 1996. Mutations in S-cone pigment genes and the absence of colour vision in two species of nocturnal primate. Proc Biol Sci 263: 705-710. 
Johnstone BM, Patuzzi R, Yates GK. 1986. Basilar membrane measurements and the travelling wave. Hear Res 22: 147-153.

Jones WD, Cayirlioglu P, Kadow IG, Vosshall LB. 2007. Two chemosensory receptors together mediate carbon dioxide detection in Drosophila. Nature 445: 86-90.

Jordt SE, Julius D. 2002. Molecular basis for species-specific sensitivity to "hot" chili peppers. Cell 108: 421-430.

Kawamura S, Kubotera N. 2004. Ancestral loss of short wave-sensitive cone visual pigment in lorisiform prosimians, contrasting with its strict conservation in other prosimians. J Mol Evol 58: 314-321.

Kevan PG, Chittka L, Dyer AG. 2001. Limits to the salience of ultraviolet: Lessons from colour vision in bees and birds. J Exp Biol 204: 25712580.

Krispel CM, Chen D, Melling N, Chen YJ, Martemyanov KA, Quillinan N, Arshavsky VY, Wensel TG, Chen CK, Burns ME. 2006. RGS expression rate-limits recovery of rod photoresponses. Neuron 51: 409-416.

Kung C. 2005. A possible unifying principle for mechanosensation. Nature 436: 647-654.

Kung C, Martinac B, Sukharev S. 2010. Mechanosensitive channels in microbes. Annu Rev Microbiol 64: 313-329.

Li M, Yu Y, Yang J. 2011. Structural biology of TRP channels. Adv Exp Med Biol 704: 1-23.

Livingstone M, Hubel D. 1988. Segregation of form, color, movement, and depth: Anatomy, physiology, and perception. Science 240: 740749 .

Lu T, Qiu YT, Wang G, Kwon JY, Rutzler M, Kwon HW, Pitts RJ, van Loon JJ, Takken W, Carlson JR, et al. 2007. Odor coding in the maxillary palp of the malaria vector mosquito Anopheles gambiae. Curr Biol 17: $1533-1544$.

Lumpkin EA, Caterina MJ. 2007. Mechanisms of sensory transduction in the skin. Nature 445: 858-865.

Lythgoe JN. 1979. The ecology of vision. Clarendon Press, Oxford.

Malnic B, Hirono J, Sato T, Buck LB. 1999. Combinatorial receptor codes for odors. Cell 96: 713-723.

Maloney LT. 1986. Evaluation of linear models of surface spectral reflectance with a small number of parameters. J Opt Soc Am A 3: $1673-1683$.

Milligan G. 2009. G protein-coupled receptor hetero-dimerization: Contribution to pharmacology and function. Br J Pharmacol 58: 5-14.

Mollon JD. 1989. “Tho she kneel'd in that Place where they grew. ..": The uses and origins of primate colour vision. J Exp Biol 146: 21-38.

Moore CA, Milano SK, Benovic JL. 2007. Regulation of receptor trafficking by GRKs and arrestins. Annu Rev Physiol 69: 451-482.

Myers BR, Sigal YM, Julius D. 2009. Evolution of thermal response properties in a cold-activated TRP channel. PLoS One 4: e5741.

Neitzel KL, Hepler JR. 2006. Cellular mechanisms that determine selective RGS protein regulation of $\mathrm{G}$ protein-coupled receptor signaling. Semin Cell Dev Biol 17: 383-389.

Niimura Y, Nei M. 2007. Extensive gains and losses of olfactory receptor genes in mammalian evolution. PLoS One 2: e708.

Niimura Y. 2009. On the origin and evolution of vertebrate olfactory receptor genes: Comparative genome analysis among 23 chordate species. Genome Biol Evol 1: 34-44.

Oka Y, Omura M, Kataoka H, Touhara K. 2004. Olfactory receptor antagonism between odorants. EMBO J 23: 120-126.

Oka Y, Takai Y, Touhara K. 2009. Nasal airflow rate affects the sensitivity and pattern of glomerular odorant responses in the mouse olfactory bulb. J Neurosci 29: 12070-12078.

Osorio D, Vorobyev M. 2008. A review of the evolution of animal colour vision and visual communication signals. Vis Res 48: 2042-2051.
Perozo E, Rees DC. 2003. Structure and mechanism in prokaryotic mechanosensitive channels. Curr Opin Struct Biol 13: 432-442.

Rasmussen SG, DeVree BT, Zou Y, Kruse AC, Chung KY, Kobilka TS, Thian FS, Chae PS, Pardon E, Calinski D, et al. 2011. Crystal structure of the $\beta 2$ adrenergic receptor-Gs protein complex. Nature 477: $549-555$.

Regan BC, Julliot C, Simmen B, Viénot F, Charles-Dominique P, Mollon JD. 2001. Fruits, foliage and the evolution of primate colour vision. Philos Trans R Soc Lond B Biol Sci 356: 229-283.

Roberts WM, Howard J, Hudspeth AJ. 1988. Hair cells: Transduction, tuning, and transmission in the inner ear. Annu Rev Cell Biol 4: 63-92.

Rosenbaum DM, Rasmussen SG, Kobilka BK. 2009. The structure and function of G-protein-coupled receptors. Nature 459: 356-363.

Ross EM, Wilkie TM. 2000. GTPase-activating proteins for heterotrimeric G proteins: Regulators of G protein signaling (RGS) and RGS-like proteins. Annu Rev Biochem 69: 795-827.

Schnapf JL, Nunn BJ, Meister M, Baylor DA. 1990. Visual transduction in cones of the monkey Macaca fascicularis. J Physiol 427: 681-713.

Schneeweis DM, Schnapf JL. 1999. The photovoltage of macaque cone photoreceptors: Adaptation, noise, and kinetics. J Neurosci 19: $1203-1216$.

Standfuss J, Edwards PC, D’Antona A, Fransen M, Xie G, Oprian DD, Schertler GF. 2011. The structural basis of agonist-induced activation in constitutively active rhodopsin. Nature 471: 656-660.

Stryer L. 1986. Cyclic GMP cascade of vision. Annu Rev Neurosci 9: 87-119.

Su CY, Martelli C, Emonet T, Carlson JR. 2011. Temporal coding of odor mixtures in an olfactory receptor neuron. Proc Natl Acad Sci 108: 5075-5080.

Su CY, Menuz K, Carlson JR. 2009. Olfactory perception: Receptors, cells, and circuits. Cell 139: 45-59.

Sukharev SI, Blount P, Martinac B, Blattner FR, Kung C. 1994. A largeconductance mechanosensitive channel in $E$. coli encoded by $m s c L$ alone. Nature 368: 265-268.

Sukharev S. 2002. Purification of the small mechanosensitive channel of Escherichia coli (MscS): The subunit structure, conduction, and gating characteristics in liposomes. Biophys J 83: 290-298.

Touhara K, Vosshall LB. 2009. Sensing odorants and pheromones with chemosensory receptors. Annu Rev Physiol 71: 307-332.

Tricas TC, Kajiura SM, Summers AP. 2009. Response of the hammerhead shark olfactory epithelium to amino acid stimuli. J Comp Physiol A Neuroethol Sens Neural Behav Physiol 195: 947-954.

Vásquez V, Sotomayor M, Cordero-Morales J, Schulten K, Perozo E. 2008. A structural mechanism for MscS gating in lipid bilayers. Science 321: $1210-1214$.

Vosshall LB. 2008. Scent of a fly. Neuron 59: 685-689.

Wang G, Carey AF, Carlson JR, Zwiebel LJ. 2010. Molecular basis of odor coding in the malaria vector mosquito Anopheles gambiae. Proc Natl Acad Sci 107: 4418-4423.

Xu F, Wu H, Katritch V, Han GW, Jacobson KA, Gao ZG, Cherezov V, Stevens RC. 2011. Structure of an agonist-bound human A2A adenosine receptor. Science 332: 322-327.

Yarmolinsky DA, Zuker CS, Ryba NJP. 2009. Common sense about taste: From mammals to insects. Cell 139: 234-244.

Yau KW. 1991. Calcium and light adaptation in retinal photoreceptors. Curr Opin Neurobiol 1: 252-257.

Yau KW, Hardie RC. 2009. Phototransduction motifs and variations. Cell 139: $246-264$.

Young T. 1802. The Bakerian lecture. On the theory of light and colours. Phil Trans Roy Soc 92: 12-48. 


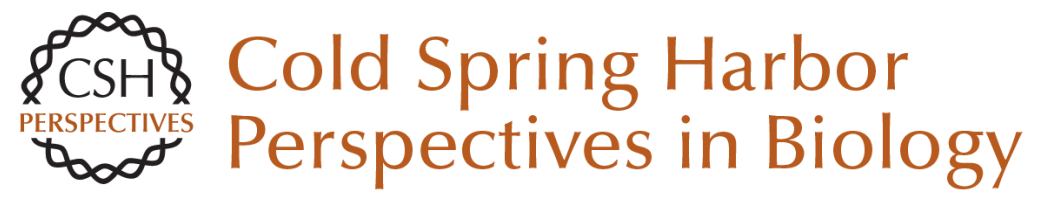

\section{Signaling by Sensory Receptors}

David Julius and Jeremy Nathans

Cold Spring Harb Perspect Biol 2012; doi: 10.1101/cshperspect.a005991 originally published online November 22, 2011

\section{Subject Collection Signal Transduction}

Cell Signaling and Stress Responses Gökhan S. Hotamisligil and Roger J. Davis

Protein Regulation in Signal Transduction Michael J. Lee and Michael B. Yaffe

Synaptic Signaling in Learning and Memory Mary B. Kennedy

Vertebrate Reproduction Sally Kornbluth and Rafael Fissore

Signaling in Lymphocyte Activation Doreen Cantrell

Signaling in Muscle Contraction Ivana Y. Kuo and Barbara E. Ehrlich

Toll-Like Receptor Signaling Kian-Huat Lim and Louis M. Staudt

Signaling Pathways that Regulate Cell Division Nicholas Rhind and Paul Russell
Second Messengers

Alexandra C. Newton, Martin D. Bootman and John D. Scott

Signals and Receptors Carl-Henrik Heldin, Benson Lu, Ron Evans, et al.

Cell Death Signaling Douglas $R$. Green and Fabien Llambi

Signaling Networks that Regulate Cell Migration Peter Devreotes and Alan Rick Horwitz

Signaling Networks: Information Flow, Computation, and Decision Making Evren U. Azeloglu and Ravi lyengar

Signal Transduction: From the Atomic Age to the Post-Genomic Era Jeremy Thorner, Tony Hunter, Lewis C. Cantley, et al.

Signaling by the TGF $\beta$ Superfamily Jeffrey L. Wrana

Subversion of Cell Signaling by Pathogens Neal M. Alto and Kim Orth

For additional articles in this collection, see http://cshperspectives.cshlp.org/cgi/collection/

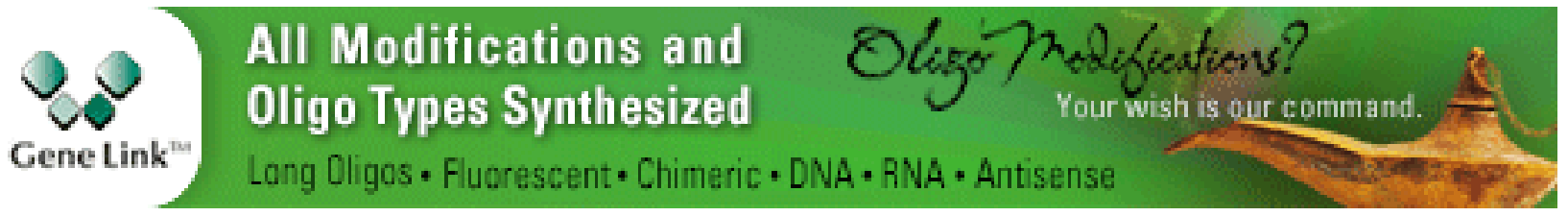

Copyright @ 2012 Cold Spring Harbor Laboratory Press; all rights reserved 